\title{
Lavandula L. - aplicação da cultura in vitro à produção de óleos essenciais e seu potencial económico em Portugal
}

\author{
SALES, H.J.S.P. ${ }^{*}$
}

'Associação BLC3 - Plataforma para o Desenvolvimento da Região Interior Centro, Av. Calouste Gulbenkian, $n 71$ Zona Industrial, 3400-060 Oliveira do Hospital, Portugal. 'Autor para correspondência: e-mail: helia.sales@blc3.pt

\begin{abstract}
RESUMO: Os óleos essenciais são metabolitos secundários que possuem diversas propriedades com elevado interesse, nomeadamente as biológicas. Estas propriedades englobam todas as atividades que esta mistura de compostos voláteis (principalmente monoterpenos, sesquiterpenos e fenilpropanóides) exerce sobre os seres humanos, animais e outras plantas. Os óleos essenciais apresentam grande valor económico, sendo os do género Lavandula dos mais comercializados e estudados devido à sua aplicabilidade industrial e propriedades terapêuticas As lavandulas são colhidas na natureza ou propagadas por técnicas convencionais, nomeadamente por estacaria. Mais recentemente, protocolos de micropropagação foram desenvolvidos para algumas espécies, permitindo a produção de plantas em larga escala disponíveis em qualquer período do ano e sem comprometer a biodiversidade das espécies. $O$ desenvolvimento de plantas tetraplóides capazes de aumentar a produção de óleo essencial nas suas flores é outro meio eficaz para aumentar potencialmente o valor das espécies de Lavandula. Em Portugal existem 5 espécies nativas do género Lavandula, amplamente distribuídas pelo país. Contudo, o seu potencial industrial permanece praticamente inexplorado e em termos de mercado o seu reconhecimento é muito reduzido. Trabalhos recentes, baseados na avaliação das propriedades biológicas dos óleos essenciais e a forma como eles podem exercer os seus efeitos contribuíram para a valorização do potencial económico das lavandulas em Portugal. Esta revisão tenta dar uma visão geral de que forma a aplicação das culturas in vitro pode levar a uma maior produção de óleos essenciais em Lavandula spp., dando especial ênfase às lavandulas nativas de Portugal.
\end{abstract}

Palavras-chave: plantas aromáticas, biotecnologia vegetal, poliploidia, revisão

ABSTRACT: Lavandula L. - application of in vitro cultivation for the essential oils production and their economic potential in Portugal. Essential oils are secondary metabolites plants and, among other features, they own several biological properties. The term "biological" includes all activities that these mixtures of volatile compounds (mainly monoterpenes, sesquiterpenes, and phenylpropanoids) maintain on humans, animals and other plants. Essential oils have great economic value, being the genus Lavandula one of the most commercialized and studied type due to its dits industrial applicability and therapeutic properties. Lavenders are harvested in the nature or propagated using traditional methodologies. More recently micropropagation protocols have been developed for several Lavandula species allowing a production of a high amount of plants available at any time of the year without compromising the biodiversity of the species. Another efficient way to potentially increase the value of Lavandula species is through the development of tetraploid plants, capable of raising the production of essential oils in flowers. In Portugal, there are 5 native species of the genus Lavandula, widely distributed throughout the country. However, native Portuguese lavenders remain mainly unexplored and have received poor recognition in markets. A recent study was carried out in order to evaluate the biological properties of the oils and also to understand how they may exercise their effects, contributing to enhance the economic potential of lavandulas in Portugal. This review attempts to provide an overview about the application of in vitro cultivations for the production of essential oils in Lavandula spp., with special emphasis on native lavandulas of Portugal.

Keywords: aromatic plants; plant biotechnology; polyploidy; review 


\section{INTRODUÇÃO}

Os óleos essenciais são metabolitos secundários de baixo peso molecular, voláteis e dotados de aroma. São formados por uma mistura complexa de vários compostos responsáveis pelas propriedades odoríferas características das plantas aromáticas (Lubbe \& Verpoorte, 2011).

Os óleos essenciais, também designados por essências, estão presentes em todo o reino vegetal, criptogâmicas e fanerogâmicas, podendo ser encontrados na maioria dos órgãos vegetais, nomeadamente, raízes, rizomas, caules, cascas, folhas, flores (mais frequentemente nas inflorescências), frutos, sementes, sendo produzidos em estruturas secretoras especializadas (externas e internas) ou resultando da hidrólise de heterósidos (Bruneton, 1991).

Durante muito tempo, estes compostos foram considerados meros catabolitos do metabolismo vegetal. Atualmente sabe-se que desempenham funções ecofisiológicas de extrema importância, que foram determinantes ao longo da evolução das espécies aromáticas. Por outro lado, os óleos essenciais são também responsáveis por várias características da própria planta, que, desde muito cedo, despertaram o interesse do Homem, constituindo, por isso, a matéria-prima de numerosas indústrias. Destaca-se, por exemplo, o seu uso na indústria farmacêutica devido às diversas propriedades biológicas que Ihes são atribuídas (Edris, 2007).

Nas últimas décadas tem-se observado um grande aumento no interesse pelo potencial terapêutico das plantas medicinais e aromáticas (Yunes et al., 2001), sendo tal facto evidenciado pelos dados de que, atualmente, cerca de $30 \%$ das drogas prescritas no mundo são obtidas direta ou indiretamente de plantas análogos semi-sintéticos ou ainda compostos sintéticos baseados em produtos naturais (Franco et al., 2007). Além disso, cerca de $50 \%$ das drogas desenvolvidas entre 1981 e 2002 foram obtidas a partir de produtos naturais ou análogos semi-sintéticos ou ainda compostos sintéticos baseados em produtos naturais (Franco et al., 2007).

Desta forma, com o incremento da procura de produtos naturais por parte da sociedade, é de vital importância o desenvolvimento e aplicação da biotecnologia no melhoramento das plantas medicinais. Para isso, a otimização de várias técnicas de micropropagação e o desenvolvimento de protocolos de melhoramento das espécies com relevância é fundamental.

Os métodos de micropropagação de plantas podem dividir-se em três tipos diferentes, consoante o material inicial e o tipo de resposta obtida. Esses tipos são a proliferação de meristemas existentes no explante original, a indução de organogénese e a formação de embriões somáticos (Canhoto, 2010).

Um género com grande importância comercial é o género Lavandula. Este género é composto por cerca de 39 espécies e diversos híbridos de plantas lenhosas perenes, algumas das quais têm sido cultivadas pelo seu teor em óleo essencial, que é extraído por destilação a vapor a partir de ramos floridos (Upson \& Andrews, 2004). Várias espécies dentro do género são plantas populares de jardins, sendo também cultivadas para comércio de flores secas, para a indústria alimentar, perfumaria, cosmética e farmacêutica, sendo as mais utilizadas a Lavandula angustifolia, L. $x$ intermedia, L. latifolia e L. stoechas (Urwin \& Mailer, 2008).

Para valorizar ainda mais economicamente este género, têm vindo a ser realizados ensaios ao nível da alteração da sua ploidia. Estes ensaios têm por base o aumento do tamanho das flores e consequentemente uma maior produção de óleos essenciais. Isto é conseguido por uma duplicação da guarnição cromossómica da planta, utilizando a colchicina (Urwin \& Mailer, 2008). A colchicina é um composto que interfere com a polimerização dos microtúbulos, impedindo a formação de uma placa metafásica normal. Em vez disso, os cromossomas ficam distribuídos na célula o que torna mais fácil a sua visualização e contagem (Canhoto, 2010).

Neste trabalho será feita uma abordagem à literatura já existente acerca dos óleos essenciais e micropropagação, mais especificamente para o género Lavandula, bem como uma revisão dos trabalhos dedicados à poliploidia das lavandulas. Por fim, será dada especial relevância às Lavandula spp. nativas de Portugal e ao seu potencial económico. Esta revisão teve por base pesquisas realizadas no âmbito de bancos de dados disponíveis on-line, artigos, livros e revistas/ jornais, quer nacionais quer internacionais, cuja área específica se enquadra na temática da biotecnologia vegetal. Esta revisão abrange um período muito alargado de anos, uma vez que pretende dar uma visão global do que se tem realizado de relevante nesta área ao longo dos anos.

\section{Plantas Aromáticas - Breve resenha histórica \\ O uso de plantas aromáticas é tão antigo} quanto a história da humanidade. Estas plantas eram empregues na medicina, na cosmética, em cerimónias religiosas e para conferir aroma e sabor aos alimentos. Os relatos mais antigos são os dos Ayurveda (há mais de 2.000 A.C.) já descrevendo técnicas rudimentares que os hindus utilizavam para a obtenção de produtos destilados, provavelmente álcoois aromáticos de espécies do 
género Cymbopogon e mirra, entre as mais de 700 substâncias aromáticas citadas. Esta técnica de destilação foi mais tarde aperfeiçoada pelo povo árabe (De La Cruz, 2006).

O Egipto parece ser o berço da arte de obtenção de óleos essenciais através da destilação, apesar de atualmente não existirem muitas referências sobre este facto. Os egípcios utilizavam os óleos essenciais em massagens para embelezar e proteger a pele do clima árido e para embalsamar os mortos, mostrando que conheciam as suas propriedades antissépticas. Estes conhecimentos espalharam-se para os antigos gregos e destes para os romanos, que eram ótimos perfumistas (De La Cruz, 2006).

Hipócrates, por vezes referido como o "pai da medicina", prescrevia fumigações de perfume (Edris, 2007).

As propriedades farmacêuticas das plantas aromáticas são parcialmente atribuídas aos óleos essenciais. O termo óleo essencial foi usado pela primeira vez no século XVI por Paracelso von Hohenheim e foi por volta deste século que houve um aumento da comercialização dos óleos essenciais, bem como uma intensificação nos estudos das suas propriedades (Edris, 2007).

Foi em 1928 que Maurice René de Gattefossé desenvolveu a técnica da aromaterapia, que utiliza óleos essenciais como terapia em vários tratamentos (Paganini, 2013).

As primeiras investigações sistemáticas dos constituintes dos óleos essenciais foram atribuídas a um químico francês M. J. Dumas (1800-1884), contudo as investigações mais importantes foram realizadas por $\mathrm{O}$. Wallach, que descobriu que muitos terpenos descritos sob diferentes nomes de acordo com a sua fonte botânica eram, na maior parte dos casos, idênticos quimicamente (Kubeczka, 2010).

\section{Óleos Essenciais - Generalidades e composição}

Os óleos essenciais são misturas complexas de compostos voláteis produzidos pelas plantas e isolados somente por processos físicos (expressão e destilação) a partir duma planta inteira, ou duma parte desta (Franz \& Novak, 2010).

Os terpenóides são os constituintes predominantes dos óleos essenciais, contudo muitos óleos são também compostos por fenilpropanóides. De facto, quase todos os óleos essenciais são extremamente complexos na sua composição, no que diz respeito à presença de uma grande variedade de compostos químicos com diferentes grupos funcionais, pertencentes a diferentes classes químicas (Sangwan et al., 2001).

Os terpenóides são compostos formados por unidades isoprénicas $\left(\mathrm{C}_{5} \mathrm{H}_{8}\right)$, sendo classificados de acordo com o número de unidades que os constituem em: hemiterpenos (uma unidade), monoterpenos (duas unidades), sesquiterpenos (três unidades), diterpenos (quatro unidades) e outros. Os monoterpenos $\left(\mathrm{C}_{10} \mathrm{H}_{16}\right)$ e os sesquiterpenos $\left(\mathrm{C}_{15} \mathrm{H}_{24}\right)$ são os mais frequentes nos óleos essenciais, podendo ocorrer na forma acíclica, monocíclica, bicíclica ou tricíclica, quer como hidrocarbonetos quer na forma de derivados funcionais oxigenados, como álcoois, éteres, aldeídos, cetonas, ésteres e fenóis (Proença da Cunha et al., 2005; FörsterFromme \& Jendrossek, 2010).

Como podemos observar na Figura 1 , a biossíntese dos terpenóides inicia-se com a condensação de dois produtos da via acetatomevalonato: o pirofosfato de isopentenilo (IPP) e o seu isómero, o pirofosfato de dimetilalilo- PPDMA (pode ser também através da via do metileritritol fosfato- MEP- oriundo de unidades de piruvato e gliceraldeído- 3-fosfato). Desta condensação resulta o pirofosfato de geranilo (GPP), percursor imediato dos monoterpenos. A adição de novas unidades de IPP a GPP constitui as reações de polimerização que originam os terpenos de maior peso molecular. Assim, o GPP ao condensar com novas unidades de IPP origina pirofosfato de farnesilo (FPP) e pirofosfato de geranilgeranilo (GGPP), percursores dos sesquiterpenos e diterpenos, respetivamente. Os diterpenos são terpenóides menos frequentes nos óleos essenciais, particularmente nos que são isolados por destilação (Sangwan et al., 2001).

\section{Funções nas plantas}

A função que os metabolitos secundários desempenham na vida da planta continua a suscitar interesse no mundo científico. Muitos deles auxiliam a síntese de outros metabólitos primários, tais como hormônios, transportadores de elétrons, fitoesteróides e carotenóides (Lima, 2009).

Sendo considerada uma resposta ecológica comum a todas as espécies vegetais, a liberação de voláteis pelos órgãos vegetativos da planta tem por objetivo a dissuasão a ataques de fitófagos ou curiosamente a atração de predadores naturais desses fitófagos, a defesa contra agentes patogénicos como fungos e bactérias, a atração de insetos auxiliares quer na polinização quer na dispersão de sementes e efeitos alelopáticos inibindo a germinação de plantas próximas. Desempenham um importante papel na economia hídrica das plantas, contribuindo na regulação da evapotranspiração ao saturarem o ambiente envolvente dos estomas, regulando igualmente a temperatura interna da planta por reflexão das radiações, proporcionada pelas propriedades das secreções de aumentarem o brilho da superfície foliar (Lima, 2009). 


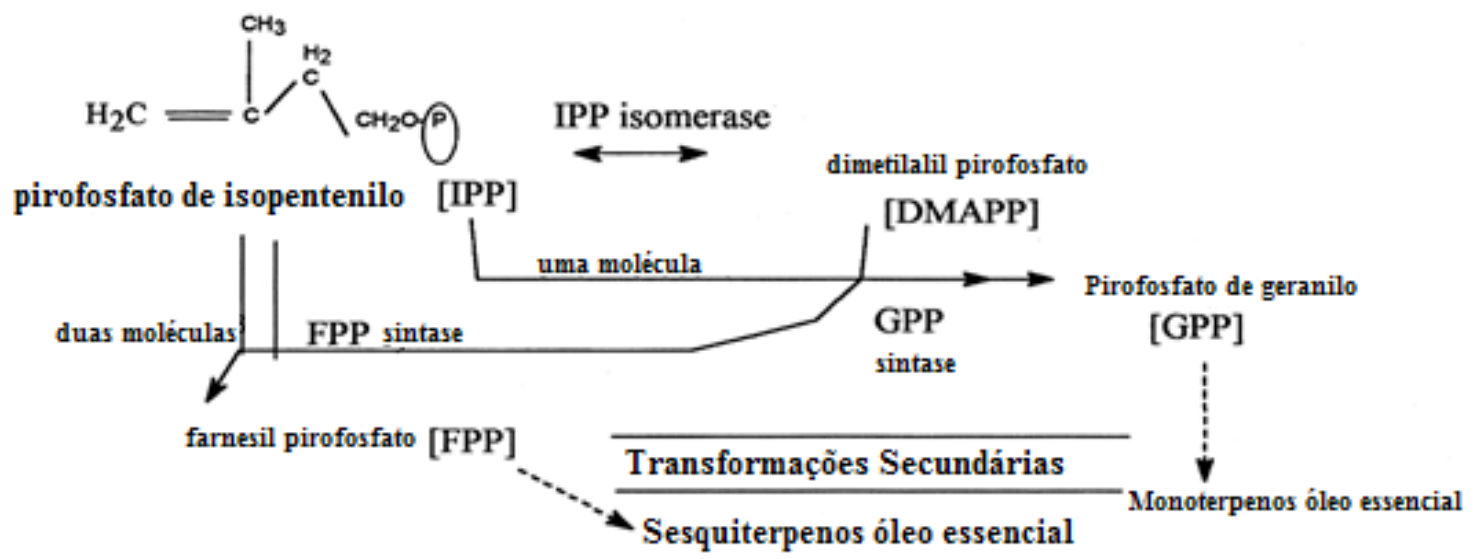

FIGURA 1. Biossíntese dos terpenóides (adaptado de Sangwan et al., 2001)

\section{O género lavandula}

O género Lavandula pertence à família Lamiaceae. Este género contém cerca de 39 espécies (Al-Bakhit et al., 2007) e inclui herbáceas anuais ou perenes, subarbustos ou arbustos de pequeno porte. A forma das folhas é diversificada em todo o género. Na maior parte das espécies as folhas são cobertas de tricomas finos, que normalmente contêm os óleos essenciais. As flores são suportadas em espirais, mantidas em inflorescências acima da folhagem, sendo que em algumas espécies as inflorescências são ramificadas. Algumas espécies produzem brácteas coloridas nos ápices. As flores podem ser azul, violeta ou lilás em espécies silvestres, ocasionalmente negro roxo ou amarelado. $O$ cálice é tubular, com cinco lóbulos, o lábio superior, muitas vezes fendido e o lábio inferior tri-fendido (Upson \& Andrews, 2004).

A grande importância económica da família Lamiaceae deve-se principalmente aos óleos essenciais produzidos nos tricomas glandulares. Tricomas glandulares são estruturas secretoras frequentemente presentes nas Lamiaceae que segregam óleos essenciais, variando o número de células secretoras, o comprimento da célula peduncular, a quantidade de óleo segregado, a densidade e o seu arranjo na epiderme (Vianna, 2009).

O género Lavandula fornece valiosos óleos essenciais, principalmente para a indústria alimentar (aromatizante), perfumaria e cosméticos, sendo também muito popular em aromaterapia (Zuzarte et al., 2011b). No entanto, outras aplicações podem ser perspetivadas, como sugerido em vários trabalhos sobre a atividade biológica deste género. Os óleos de Lavandula têm sido relatados como tendo propriedades sedativas e antiespasmódicas (Cavanagh \& Wilkinson, 2002), bem como tendo atividade acaricida (Oliveira, 2009), antibacteriana
(Adaszyńska et al., 2013), antifúngica (Zuzarte et al., 2013) e antioxidante (Kačániová et al., 2014). Foi também sugerido a aplicação dos óleos de Lavandula como biopesticidas (González-Coloma et al., 2011).

\section{Lavandula spp. - a sua importância}

As espécies do género Lavandula são das mais populares ervas medicinais, com grande interesse económico (Al-Bakhit et al., 2007).

Os óleos essenciais deste género são estritamente regulados por normas internacionais da ISO (Organização Internacional de Normalização) (ISO TC 54 - ISO/CD 8902, 2007; ISO TC 54 $\mathrm{N}$-ISO/WD4719, 2009) e durante os últimos anos a exploração económica de espécies nativas de Lavandula tem aumentado, devido a um renovado interesse no uso destes compostos de origem natural (Zuzarte et al., 2010).

Como já foi anteriormente referido, o género Lavandula possui propriedades com grandes aplicações para o Homem. Desde a indústria farmacêutica, à alimentar, passando pela cosmética e na agricultura, as lavandulas possuem uma importância económica bastante elevada, em particular os seus óleos essenciais, sendo - comércio de algumas espécies de Lavandula bastante elevado (Brud, 2010; Franz \& Novak, 2010). Em Portugal Continental, numa avaliação preliminar, com dados fornecidos por alguns produtores de plantas aromáticas e medicinais ativos, foi possível identificar uma produção de $4200 \mathrm{~kg}$ no que toca às lavandulas cultivadas e espontâneas e relativamente aos seus óleos essenciais, uma produção de 105 kg (Figueiredo et al., 2014).

O óleo essencial de Lavandula spp. possui inúmeros constituintes, cujas proporções variam de espécie para espécie. Porém, dos componentes majoritários que se podem encontrar nos óleos de Lavandula spp. destacam-se 1,8-cineole (Zuzarte et 
al., 2011a), carvacrol, cis- $\beta$-ocimeno (Zuzarte et al., 2011b), cânfora e fenchona (Zuzarte et al., 2010). As estruturas químicas destes compostos encontramse representadas na Figura 2.

\section{Lavandula spp. - propagação in vitro}

Os metabolitos resultantes das espécies de Lavandula podem ser obtidos a partir de plantas selvagens nos campos de cultivo ou a partir de plantas cultivadas. No entanto, por razões ambientais resultantes da colheita de grandes quantidades de plantas que crescem no campo, esta deve ser evitada, uma vez que pode ameaçar as espécies e reduzir a sua biodiversidade. Portanto, a atenção deve ser deslocada para o desenvolvimento de protocolos eficazes para a propagação de plantas, a fim de produzir uma grande quantidade a partir do qual os produtos químicos de interesse podem ser extraídos, impedindo assim a exploração das populações selvagens (Zuzarte et al., 2010).

Técnicas de cultura de tecidos foram aplicadas a várias espécies de Lavandula. Por exemplo a proliferação de meristemas (desenvolvimento de meristemas já existentes no explante e o ulterior enraizamento dos rebentos caulinares deles resultantes (Canhoto, 2010)) foi reportado em Lavandula dentata (Jordan et al., 1998; Sudriá et al., 1999, 2001; Echeverrigaray et al., 2005), Lavandula latifolia (Sánchez-Gras \& Calvo, 1996), Lavandula vera (Andrade et al., 1999) e Lavandula pedunculata (Zuzarte et al., 2010).

A formação direta de caules a partir de explantes de diferentes tecidos (organogénese direta) foi descrito em L. latifolia (Calvo \& Segura, 1989a) e formação de caules a partir de calos (organogénese indireta) foi relatado em Lavandula angustifolia (Quazi, 1980; Ghiorghita et al., 2009), Lavandula x intermedia (Dronne et al., 1999), L. latifolia (Calvo \& Segura, 1988, 1989b; Jordan et al., 1990), Lavandula officinalis x L. latifolia (Panizza \& Tognoni, 1988) e L. vera (Tsuro et al., 1999, 2000). Um estudo preliminar sobre a embriogénese somática (formação de um embrião a partir de uma célula somática, não envolvendo gâmetas ou produtos de fusão gamética (Canhoto, 2010)) de $L$. vera foi realizado por Kintzios et al., 2002. Quanto à secção stoechas, onde L. pedunculata está incluída, a micropropagação através da proliferação de gemas axilares foi obtida apenas para Lavandula stoechas (Nobre, 1996) e Lavandula viridis (Dias et al., 2002; Nogueira \& Romano, 2002).

Desta forma, é importante desenvolver novos protocolos relativos à embriogénese somática em Lavandula spp., uma vez que é a técnica de micropropagação menos aplicada e desenvolvida neste género.

\section{Lavandula spp. - tetraplóides}

A duplicação cromossómica usando colchicina tem vindo a ser utilizada nos programas de melhoramento de plantas. O resultado são plantas poliplóides que muitas vezes têm folhas, flores, frutos e sementes mais desenvolvidas. A poliploidia é comum e tem desempenhado um papel importante na evolução das plantas com flor, sendo que a poliploidia natural está presente na família Lamiaceae, como por exemplo em Thymus, Glechoma e Lavandula (Urwin \& Horsnell, 2007).

A contagem de cromossomas em $L$. angustifolia varia consideravelmente na literatura entre $2 n$ estimado entre 36 e 54 . O número de cromossomas estimados nesta espécie sugere que é uma espécie poliplóide antiga (Urwin \& Horsnell, 2007).

Como já foi referido anteriormente o género Lavandula é rico em propriedades muito úteis ao Homem. Desta forma, todo o melhoramento que se conseguir obter destas plantas, quer a nível da quantidade quer ao nível da qualidade, trará um valor acrescentado.

Face a esta perspetiva de melhoramento e numa tentativa de produzir maior rendimento na produção de óleo essencial de lavandulas, utilizouse a colchicina para induzir uma poliploidia na espécie Lavandula angustifolia. Os ensaios tiveram sucesso e os resultados foram promissores, uma vez que as lavandulas autotetraplóides obtidas, comparativamente aos exemplares diplóides, possuíam pedúnculos mais espessos, flores e sementes de maiores dimensões, tricomas glandulares peltados maiores e existência de diferentes tipos de tricomas capitados nas folhas. Assim conseguiu-se obter plantas em que a produção de óleos essenciais era superior às das

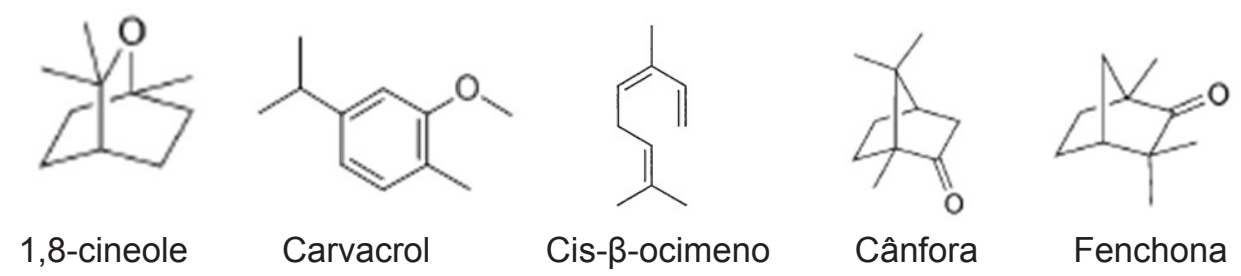

FIGURA 2. Estruturas químicas dos compostos majoritários de Lavandula spp. (adaptado de Zuzarte et al., 2009)

Rev. Bras. PI. Med., Campinas, v.17, n.4, supl. II, p.992-999, 2015. 
plantas selvagens (Urwin \& Horsnell, 2007).

Desta forma, pode-se inferir que em ensaios futuros, utilizando outras espécies ou híbridos, os resultados obtidos também poderão ser bastante promissores, quer no melhoramento da produção de óleos quer no melhoramento dos cultivares com vista à ornamentação (Urwin \& Horsnell, 2007).

\section{Distribuição em portugal e potencial de desenvolvimento industrial}

No que diz respeito a Portugal, estão identificadas cinco espécies: $L$. pedunculata, $L$. viridis, L. latifolia, L. multifida e L. luisieri $(=L$. stoechas subsp. luisieri) (Zuzarte, 2012). Estas espécies têm diferentes distribuições: $L$. latifolia ocorre numa região muito limitada, perto da cidade de Coimbra; L. multifida pode ser encontrada em determinadas regiões nomeadamente Arrábida, Sesimbra e Mértola, enquanto as espécies da secção Stoechas estão amplamente distribuídas L. viridis ocorre no Sul, L. pedunculata juntamente com $L$. luisieri estão distribuídas por todo o país (Zuzarte, 2012).

Atualmente, apenas duas espécies se destacam com valor económico relevante em Portugal: L. latifolia (alfazema-brava) e L. stoechas (rosmaninho-menor) são muito utilizadas na indústria dos sabonetes, óleos essenciais, flores secas e como plantas ornamentais (Upson \& Andrews, 2004).

Apesar da grande popularidade destas lavandulas nativas de Portugal o seu potencial industrial permanece praticamente inexplorado e em termos de mercado o seu reconhecimento é muito reduzido. A falta de estudos de base científica, bem como a ausência de garantia de produtos finais de alta qualidade são, em parte, responsáveis por esta situação (Zuzarte, 2012).

Tendo em conta o potencial económico das lavandulas e a reduzida informação sobre as espécies que crescem espontaneamente em Portugal, um estudo científico baseado na avaliação das propriedades biológicas dos óleos essenciais e a forma como eles podem exercer os seus efeitos foi concretizado por Zuzarte (2012).

Através deste estudo foi possível a valorização das espécies de lavandula de crescimento espontâneo em Portugal, com vista a uma maior exploração económica. Esta valorização foi concretizada através da avaliação da bioatividade dos óleos essenciais para futura aplicação no sector da saúde, nomeadamente na avaliação da atividade antifúngica e potencial anti-inflamatório e no sector da agricultura, no que toca ao potencial dos óleos com efeitos antifúngicos, nematicidas e de repelência contra insetos (Zuzarte, 2012).

\section{CONCLUSÕES}

Cada vez mais há uma procura exponencial das plantas aromáticas e dos seus produtos. Cada vez mais o Homem tenta recorrer à natureza e ao que é natural para satisfazer as suas necessidades do dia-a-dia. Assim, todos os estudos na área das plantas aromáticas são essenciais para que novas propriedades e aplicações sejam descobertas.

Dos 52 estudos analisados neste trabalho, 6 comprovam as propriedades antifúngicas, antibacterianas, acaricidas, antioxidantes, biopesticidas, sedativas e antiespasmódicas dos óleos de Lavandula spp.

Relativamente à micropropagação, 21 trabalhos desenvolveram novos protocolos no que toca à proliferação de meristemas, proliferação de gemas axilares, organogénese direta, organogénese indireta e embriogénese somática.

Quanto às lavandulas em Portugal, destacam-se os trabalhos dos autores Zuzarte, Dias e Nobre, quer na área da micropropagação (desenvolvimento de novos protocolos), quer na área dos óleos essenciais (caracterização química e bioactividade).

Uma vez que o âmbito das plantas aromáticas e medicinais é uma área emergente em todo o mundo, é de especial interesse o desenvolvimento de novos protocolos que visem o melhoramento das espécies, permitindo não só uma maior valorização económica mas também em termos de preservação, a fim da biodiversidade vegetal ser conservada.

\section{REFERÊNCIA}

ADASZYŃSKA, M. et al., A. Comparison of chemical composition and antibacterial activity of lavender varieties from Poland. Natural Product Research, v.27, n.16, p.1497-1501, 2013.

AL-BAKHIT, A.A.M. et al. In vitro propagation of two Lavandula species: Lavandula angustifolia and Lavandula latifolia L. Medica. Jordan Journal of Agricultural Sciences, v.3, n.1, p.16-24, 2007.

ANDRADE, L.B. et al. The effect of growth regulators on shoot propagation and rooting of common lavender (Lavandula vera DC). Plant Cell, Tissue and Organ Culture, v.56, p.79-83, 1999.

BRUD, W.S. Industrial Uses of Essential Oils. In: BASER K.H.C.; BUCHBAUER, G. Handbook of Essential Oils, Science, Technology and Applications. CRC Press, 2010. p.843-854.

BRUNETON, J. Pharmacognosie, Phytochimie, Plantes Médicinales. 2.ed. Lavoisier. Paris. 1991. 993p.

CALVO, M.C.; SEGURA, J. In vitro propagation of lavander. HortScience, v.24, p.375-376, 1989a

CALVO, M.C.; SEGURA, J. Plant regeneration from cultured leaves of Lavandula latifolia Medicus: influence of growth regulators and illumination conditions. Plant

Rev. Bras. PI. Med., Campinas, v.17, n.4, supl. II, p.992-999, 2015. 
Cell, Tissue and Organ Culture, v.19, p.33-42, 1989b.

CALVO, M.C.; SEGURA, J. In vitro morphogenesis from explants of Lavandula latifolia and Lavandula stoechas seedlings. Scientia Horticulturae, v.36, p.131-137, 1988.

CANHOTO, J. Biotecnologia Vegetal - da clonagem de plantas à transformação genética. 1.ed. Imprensa da Universidade de Coimbra. 2010. 407p.

CAVANAGH, H.M.A.; WILKINSON, J.M. Biological activities of lavender essential oils. Phytotherapy Research, v.16, p.301-308, 2002.

DE LA CRUZ, M. O uso de óleos essenciais na acupunctura. 2006. 89p. Dissertação (Programa de pós-graduação em acupunctura) - Universidade de Cuiabá, Cuiabá.

DIAS, M.C. et al. Rapid clonal multiplication of Lavandula viridis L'Her through in vitro axillary shoot proliferation. Plant Cell, Tissue and Organ Culture, v.68, p.99-102, 2002.

DRONNE, S. et al. A simple and efficient method for in vitro shoot regeneration from leaves of lavandin (Lavandula $\mathrm{x}$ intermedia Emeric ex Loiseleur). Plant Cell Reports, v.18, p.429-433, 1999.

ECHEVERRIGARAY, S. et al. Micropropagation of Lavandula dentata from axillary buds of field-grown adult plants. Biologia Plantarum, v.49, n.3, p.439-442, 2005.

EDRIS, A.E. Pharmaceutical and therapeutic potentials of essential oils and their individual volatile constituents: a review. Phytotherapy Research, v.21, p.308-323, 2007.

FIGUEIREDO, A.C. et al., Plantas aromáticas e medicinaisóleos essenciais e voláteis. Revista da Associação Portuguesa de Horticultura, n.114, p.29-33, 2014.

FÖRSTER-FROMME, K.; JENDROSSEK, D. Catabolism of citronellol and related acyclic terpenoids in pseudomonads. Applied Microbiology and Biotechnology, vol.87, n.3, p.859-869, 2010.

FRANCO, A.L.P. et al. Evaluation of the chemical composition and antibacterial activity of essential oils of Aloysia gratissima (Gillies \& Hook) Tronc.,Ocimum gratissimum L. and Curcuma longa L. Revista Electrônica de Farmácia, vol.4, p.208-220, 2007.

FRANZ, C.; NOVAK, J. Sources of Essential Oils. In: BASER, K.H.C.; BUCHBAUER, G. Handbook of Essential Oils, Science, Technology and Applications. CRC Press, 2010. p.39-82.

GHIORGHITA, G. et al. Some aspects concerning the in vitro reaction of Lavandula angustigolia L. Propagation of ornamental plants, v.9, n.1, p.47-49, 2009.

GONZÁLEZ-COLOMA, A. et al. Chemical and biological profiles of Lavandula luisieri essential oils from western Iberia Peninsula populations. Biochemical Systematics and Ecology, v.39, p.1-8, 2011.

JORDAN, A. et al. Micropropagation of adult Lavandula dentata plants. The Journal of Horticultural Science and Biotechnology, v.73, p.93-96, 1998.

JORDAN, A. et al. Morphogenesis in callus and single-cell cultures of Lavandula latifolia Medicus. The Journal of Horticultural Science and Biotechnology, v.65, p.49-53, 1990.

KAČÁNIOVÁ, M. et al. Antibacterial activity against Clostridium genus and antiradical activity of the essential oils from different origin. Journal of Environmental Science and Health, Part B: Pesticides, Food
Contaminants, and Agricultural Wastes, v.49, p.505512, 2014.

KINTZIOS, S. et al. The effects of light on callus growth and somatic embryogenesis from Lavandula vera and Teucrium chamaedrys: a preliminary study. Journal of Herbs, Spices \& Medicinal Plants, v.9, n.2, p.223227, 2002.

KUBECZKA, K. History and Sources of Essential Oil Research. In: BASER, K.H.C.; BUCHBAUER, G. Handbook of Essential Oils, Science, Technology and Applications. CRC Press, 2010. p.3-38.

LIMA, A.S.B. Estratégias para caracterização molecular de espécies aromáticas da flora Portuguesa. 2009. 62p. Dissertação (Mestrado em biologia celular e biotecnologia), Departamento de Biologia Vegetal, Faculdade de Ciências, Universidade de Lisboa, Portugal.

LUBBE, A.; VERPOORTE, R. Cultivation of medicinal and aromatic plants for specialty industrial materials. Industrial Crops and Products, v.34, p.785-801, 2011.

NOBRE, J. In vitro cloning and micropropagation of Lavandula stoechas from field-grown plants. Plant Cell, Tissue and Organ Culture, v.46, p.151-155, 1996.

NOGUEIRA, J.M.F.; ROMANO, A. Essential oils from micropropagated plants of Lavandula viridis. Phytochemical Analysis, v.13, p.4-7, 2002.

OLIVEIRA, R.S.B. Atividade acaricida contra ácaros Dermatophagoides pteronyssinus e $D$. farinae (Pyroglyphidae) de produto contendo óleos essenciais de Lavadula officinalis e Mentha piperita (Labiatae). 2009. 177p. Dissertação (Doutoramento em Saúde da Criança e do Adolescente), Faculdade Ciências Médicas, Universidade Estadual de Campinas, Brasil.

PAGANINI, T. Bem-estar e qualidade de vida: a aromaterapia no cuidado ao estresse. 2013. 111p. Dissertação (programa de pós-graduação em saúde e gestão do trabalho), Universidade do Vale do Itajaí, Santa Catarina, Brasil.

PANIZZA, M.; TOGNONI, F. Clonal propagation, callus formation and plant regeneration of Lavandin. Scientia Horticulturae, v.37, p.157-163, 1988.

PROENÇADA CUNHA, A.; CAVALEIRO, C.; SALGUEIRO, L. Fármacos aromáticos (Plantas aromáticas e óleos essenciais). In: PROENÇA DA CUNHA, A. (2.Ed.). Farmacognosia e Fitoquímica. Fundação Calouste Gulbenkian. Lisboa. 2005. p.338-401.

QUAZI, M.H. In vitro multiplication of Lavandula spp. Annals of Botany, v.45, p.361-362, 1980.

SANCHEZ-GRAS, M.C.; CALVO, M.C. Micropropagation of Lavandula latifolia through nodal bud culture of mature plants. Plant Cell, Tissue and Organ Culture, v.45, p.259-261, 1996.

SANGWAN, N.S. et al. Regulation of essential oil production in plants. Plant Growth Regulation, v.34, p.3-21, 2001.

SUDRIÁ, C. et al. Effect of benzyladenine and indolebutyric acid on ultrastructure, glands formation, and essential oil accumulation in Lavandula dentata plantlets. Biologia Plantarum, v.44, n.1, p.1-6, 2001.

SUDRIÁ, C. et al. Influence of plant growth regulators on the growth and essential oil content of cultured Lavandula dentata plantlets. Plant Cell, Tissue and

Rev. Bras. PI. Med., Campinas, v.17, n.4, supl. II, p.992-999, 2015. 
Organ Culture, v.58, p.177-184, 1999.

TSURO, M. et al. Efficient plant regeneration from multiple shoots formed in the leaf-derived callus of Lavandula vera, using the "open culture system". Scientia Horticulturae, v.86, p.81-88, 2000.

TSURO, M. et al. Comparative effect of different types of cytokinin for shoot formation and plant regeneration from leaf-derived callus of lavender (Lavandula vera DC). Scientia Horticulturae, v.81, p.331-336, 1999.

UPSON, T.; ANDREWS, S. The genus Lavandula. 1.ed. Royal Botanic Gardens, Kew, 2004. 442p.

URWIN, N.A.R.; MAILER, J. Oil Content and fatty acid profiles of seed oil from the genus Lavandula. Journal of the American Oil Chemists' Society, v.85, p.491492, 2008.

URWIN, N.A.R.; HORSNELL, J. Generation and characterization of colchicine-induced autotetraploid Lavandula angustifolia. Euphytica, v.156, p.257-266, 2007.

VIANNA, J.S. Caracterização anatômica, morfológica e química de quimiotipos de Ocimum gratissimum Lineu. 2009. 78p. Dissertação (Mestrado em ciências agrárias), Faculdade de Agronomia e Veterinária, Universidade de Brasília, Brasil.

YUNES, R.A. et al. Fármacos e fitoterápicos: a necessidade do desenvolvimento de fitoterápicos e fitofármacos no
Brasil. Química Nova, v.24, n.1, p.147-152, 2001.

ZUZARTE, M. et al. Antifungal and anti-inflammatory potential of Lavandula stoechas and Thymus herbabarona essential oils. Industrial Crops and Products, v.44, p.97-103, 2013.

ZUZARTE, M. Portuguese lavenders: evaluation of their potential use for health and agricultural purposes. 2012. 269p. Dissertação (Doutoramento em Biologia, especialização em Fisiologia Vegetal), Faculdade de Ciências e Tecnologia, Universidade de Coimbra, Portugal.

ZUZARTE, M. et al. Chemical composition and antifungal activity of the essential oils of Lavandula viridis L'Hér. Journal of Medical Microbiology, v.60, p.612-618, 2011a.

ZUZARTE, M. et al. Antifungal activity of phenolic-rich Lavandula multifida L. essential oil. European Journal of Clinical Microbiology \& Infectious Diseases, v.3, p.1359-1366, 2011b.

ZUZARTE, M. et al. Trichomes, essential oils and in vitro propagation of Lavandula pedunculata (Lamiaceae). Industrial Crops and Products, v.32, p.580-587, 2010.

ZUZARTE, M. et al. Chemical Composition and Antifungal Activity of the Essential Oils of

Lavandula pedunculata (Miller) Cav. Chemistry \& Biodiversity, v.6, p.1283-1292, 2009. 